\title{
Probing electrosynthetic reactions with furfural on copper surfaces
}

Received 00th January 20xx, Accepted 00th January 20xx

DOI: $10.1039 / x 0 x \times 00000 x$

\author{
Junnan $\mathrm{Li}^{\mathrm{a}}$ and Nikolay Kornienko ${ }^{\mathrm{a} *}$
}

This work entails the integrated use of electrochemistry and operando Raman spectroscopy to probe the reduction of a biomass platform, furfural, to value-added chemicals on $\mathrm{Cu}$ electrodes. The results reveal key strutural differences of the $\mathrm{Cu}$ that dictate selectivity for furfural alcohol or 2-methylfuran.

Given the increasingly evident consequences of unmitigated fossil fuel consumption, there is a renewed focus on developing alternative sustainable technologies. ${ }^{1}$ To this end, the innovation of renewable electricity-driven processes to replace current thermochemical ones is particularly attractive. ${ }^{2-4}$ Ideally, such systems convert abundant reactants such as water, $\mathrm{CO}_{2}$ or biomass (the focus of this work) into the fuels and chemicals necessary to power modern society.

At the heart of electrosynthetic technologies is the catalyst which plays a large role in determining the system's efficiency, selectivity, stability, and consequently economic viability. Underpinning the development of such highly performant catalysts is the fundamental understanding of how they function at a molecular level. Against this backdrop, this work utilized an approach that combined electrochemical experiments and operando spectroscopy, that is, spectroscopy performed on the catalytic system as it is functioning.

The reaction of choice here was the electrochemical reduction of furfural, a biomass platform readily obtained from the dehydration of sugars. ${ }^{5-7}$ While furfural is only modestly valuable, its reduction products of furfural alcohol (FA) and 2methylfuran (2MF), widely used in resin production, flavourings, and alternative fuels. ${ }^{5,6,8}$ In parallel, we chose $\mathrm{Cu}$ as the electrode material as it is inexpensive and has been shown to be active for such reactions in the past. ${ }^{9-12}$ The particular contribution in this work is the novel extracted insights into the reaction mechanism on Cu surfaces through

${ }^{a}$ Department of Chemistry, Université de Montréal, 1375 Ave. Thérèse-Lavoie-Roux, Montréal, QC H2V OB3

*email: Nikolay.kornienko@umontreal.ca

Electronic Supplementary Information (ESI) available: [materials characterization, reaction parameters, additional spectroscopic and catalytic results]. See DOI: $10.1039 / x 0 x \times 00000 x$ a

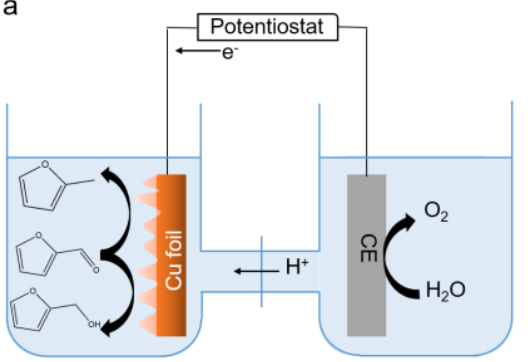

b

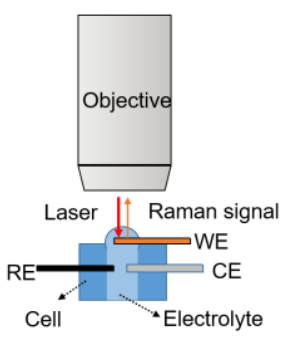

Figure 1: Illustration of the approach of this work in using electrochemistry (a) and operando Raman spectroscopy (b) to develop a mechanistic understanding of furfural reduction on heterogeneous $\mathrm{Cu}$ electrodes.

the evaluation of both roughened and single crystal Cu surfaces and operando Raman spectroscopy (Fig. 1).

In general, the reduction of furfural on Cu surfaces is believed to proceed through hydrogenation with surface hydrogen species and is also steered by applied potential, reactant concentration, type of electrolyte and $\mathrm{pH}$ used.7, 9, 11, 13-15 However, comparatively less is known in terms of how catalystreactant interactions dictate the reaction at a molecular level. As a starting point, we used electrochemically roughened $\mathrm{Cu}(\mathrm{R}$ $\mathrm{Cu}$ ) electrodes as model high-surface area catalysts which are free of any surface ligands and would also be suitable to use as surface-enhanced Raman (SER) substrates. R-Cu electrodes were generated by electrochemically cycling a polished polycrystalline $\mathrm{Cu}$ foil, resulting in an oxide-derived $\mathrm{R}-\mathrm{Cu}$ material (Fig. 2a). ${ }^{16}$ Transmission electron microscopy (TEM) (Fig. 2b, S1) and scanning electron microscopy (SEM) (Fig. 2c) revealed the prevalence of a flake-like morphology on the surface as a result of the roughening procedure. X-ray diffraction (XRD) (Fig. 2d), X-ray photoelectron spectroscopy (XPS) (Fig. 2e,f) indicated that the R-Cu is predominantly in the $\mathrm{Cu}^{(0)}$ state but has a surface covered by an amorphous $\mathrm{CuO}_{x}$ layer. 


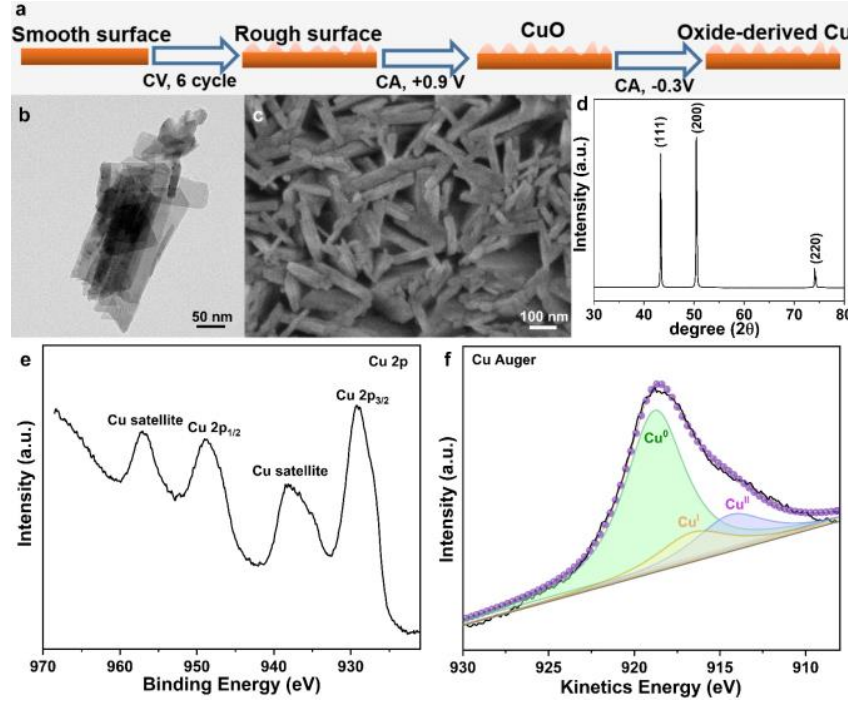

Figure 2: Synthetic procedure of $\mathrm{R}-\mathrm{Cu}(\mathrm{a})$ alongside of TEM (b), SEM (c), XRD (d) and XPS (e, f) of the resultant material.

The $\mathrm{R}-\mathrm{Cu}$ was first tested in a $\mathrm{pH} 3$ electrolyte in a conventional 3-electrode electrochemical setup through cyclic voltammetry (CV). In the absence of furfural, reductive catalytic current due to the hydrogen evolution reaction (HER) initiated at approximately $-0.4 \mathrm{~V}$ vs. the reversible hydrogen electrode (RHE) (Fig. 3a). A noticeable enhancement in the catalytic current was evident upon the addition of furfural to the electrolyte in otherwise similar conditions. To initially optimize the reaction conditions, different amount of furfural was added in the electrolyte and CV curves are recorded. When the concentration of furfural was $59 \mathrm{mM}$, the current density was maximal (Fig S2a). Higher concentrations may lead to surface saturation and inhibit proton reduction necessary for furfural hydrogenation.

Product quantification (NMR for liquid, gas chromatography (GC), for gas) was then used to probe the reactions occurring. At $-0.426 \mathrm{~V}$, the earliest potential in which products accumulated in sufficient quantities, the main products were FA and 2-MF, alongside of a minor amount of hydrogen gas (Fig 3b). At more negative potentials, the Faradaic efficiency (FE) for FA and 2-MF decreased progressively with potential. This occurrence was likely due to an increase of undesirable reaction pathways involving dimerization or ring-opening reactions driven by the highly negative applied potentials or homogeneous side reactions occurring in the reaction medium. ${ }^{12,15}$

Next, to probe the mechanism of this reaction on the $\mathrm{R}-\mathrm{Cu}$ surface, we turned to operando Raman spectroscopy. This technique, alongside of complementary infrared and other related techniques, is playing a significant role in enhancing the community's understanding of catalyst transformations, reaction pathways, and in general, how to rationally design next-generation materials for electrosynthetic systems. ${ }^{17,} 18$ In this experiment, we used a $633 \mathrm{~nm}$ laser, custom spectroelectrochemical cells and immersion objectives to
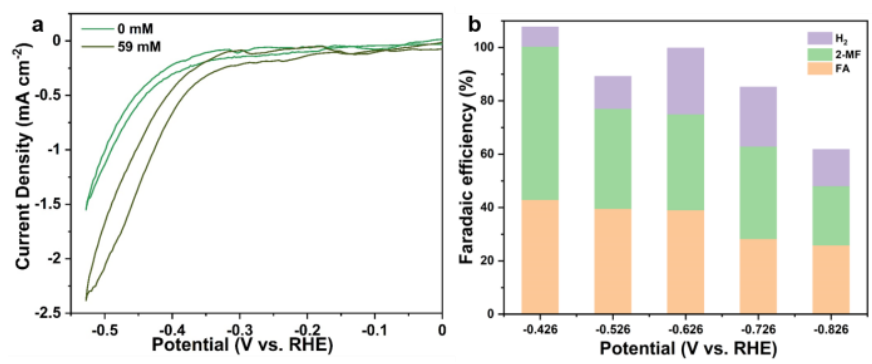

Figure 3: CV scans of the R-Cu electrodes in the ansence and presence of furfural (a) and product selectivity as a function of applied potential (b).

acquire SER spectra but otherwise, the electrochemical conditions were the same. The resultant spectra were assigned on the basis of previous theoretical and experimental investigations. ${ }^{19-21}$ Further, comparison to spectra of the R-Cu in the electrolyte without furfural present (Fig S3) and through surveying the literature enabled us to verify that the peaks not assigned in Figure 4 can be attributed to electrolyte species.

The spectra are divided into 3 distinct regions: the low frequency region which exhibits bands related to the catalystintermediate bands (Fig. 4a), the high frequency region which features marker bands related to furfural and the products and the high-frequency region containing the $\mathrm{Cu}-\mathrm{H}$ stretch. OP denotes the spectra at open circuit and OP-2 signifies spectra at open circuit following the stepped chronoamperometry used for potential-dependent spectra. First, looking at the low frequency region, the surface of the $\mathrm{R}-\mathrm{Cu}$ is covered by an amorphous layer of oxidized copper $\left(\mathrm{CuO}_{\mathrm{x}}\right){ }^{16}, 22,23$ As the potential is progressively increased, the $\mathrm{CuO}_{x}$ is reduced away to metallic $\mathrm{Cu}$ and several new bands appear. $\mathrm{Cu}-\mathrm{H}$ intermediates from the reduction of aqueous protons appear, as do $\mathrm{Cu}-\mathrm{C}$ and $\mathrm{Cu}-\mathrm{O}$ intermediates, the latter two only detected in furfural containing solutions. The alternative possibility would be that these modes come from different types of surface sites or binding motifs. In general, unmarked bands are thought to originate from other electrolyte species as they are present in the spectra of the R-Cu without furfural.

In the medium frequency region, the spectrum at open circuit indicated that the aldehyde group of furfural was possible hydrated or distorted through interactions with the Cu surface, as seen before with $\mathrm{Ag}^{20}$ However, the rest of the furfural marker bands were easily seen. At progressively negative potentials, the furfural bands disappeared and $\mathrm{C}=\mathrm{C}$ bands attributed to FA and 2-MF appeared. Several bands in the 1580$1612 \mathrm{~cm}^{-1}$ region may indicate a distribution of different intermediate on the surface en route to FA and 2-MF products. Unfortunately, the similarity of the FA and 2-MF spectra made it impossible to unambiguously distinguish between them. Compared with Figure $4 \mathrm{~b}$, Raman spectrum on $\mathrm{R}-\mathrm{Cu}$ without addition of furfural showed a completely different result (Fig $\mathrm{S} 3 \mathrm{~b})$. No $\mathrm{C}$ species were observed under this condition. This confirms that the peaks which were observed in Figure $4 \mathrm{~b}$ is attributed to FA or 2-MF intermediates. Because reaction intermediates were readily seen at potentials more positive than reduction products could be detected in the bulk reaction, 
a

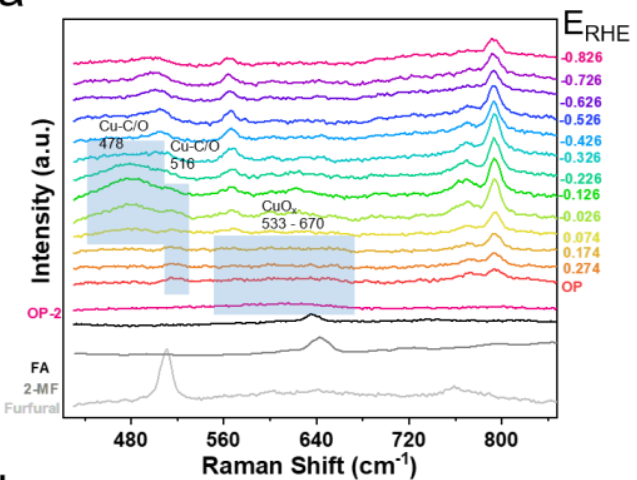

b

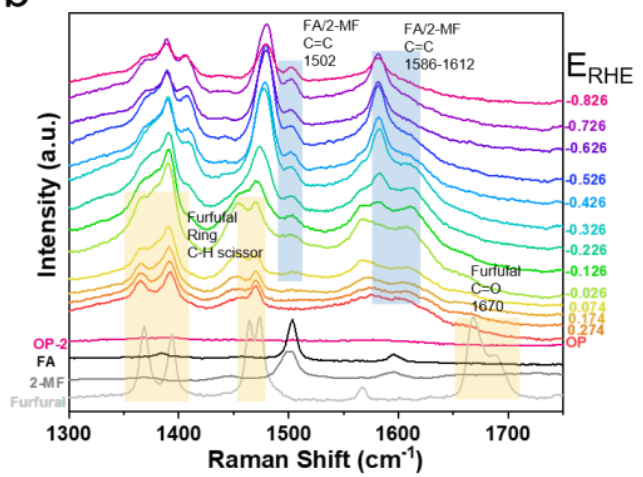

C

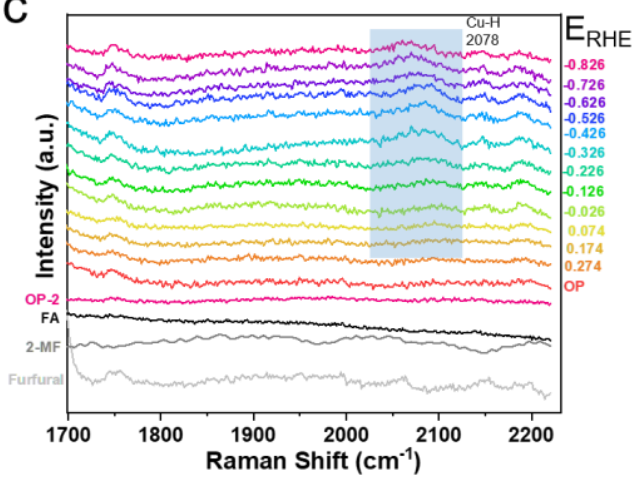

Figure 4: Operando SER spectra of furfural reduction on R-Cu surfaces in the low frequency (a) and medium frequency (b) and high frequency (c) regions.

we postulate that the adsorption and initial reduction steps occur readily once the $\mathrm{CuO}_{x}$ layer is reduced away while the rate-limiting steps, in turn, are the hydrogenation and desorption of the intermediates. Finally, the high frequency region spectra, containing the typical $\mathrm{M}-\mathrm{H}$ stretch, ${ }^{24-26}$ indicated that hydrogen species become adsorbed strongly after -0.326 $\mathrm{V}_{\mathrm{RHE}}$. This occurs after the $\mathrm{Cu}-\mathrm{C} / \mathrm{O}$ intermediate bands appear and point to the hydrogenation of the intermediates after their adsorption being rate-limiting.

Because the R-Cu contained a variety of surface crystal facets and possible active sites, we sought to utilize single-crystal copper substrates as the next step. Figure S2b shows that $\mathrm{Cu}$ (110) showed the highest current density among the three single crystal $\mathrm{Cu}$ catalyst. The current density of the addition of furfural is higher than without furfural (Figure S4). Using (100),
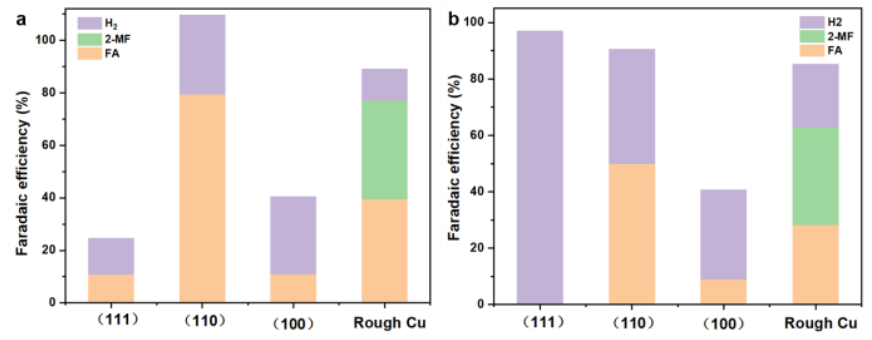

Figure 5: Product distribution of single crystal and R$\mathrm{Cu}$ electrodes at $-0.526(\mathrm{a})$ and $-0.726 \mathrm{~V}_{\mathrm{RHE}}(\mathrm{b})$.

(110) and (111) Cu substrates in an identical configuration as the $\mathrm{R}-\mathrm{Cu}$, we measured the product distribution at -0.526 and $0.726 \mathrm{~V}_{\mathrm{RHE}}$. Interestingly, none of the electrodes generated any detectable 2-MF and only $\mathrm{Cu}(110)$ generated a significant amount of FA. This last observation indicates that $\mathrm{Cu}(110)$ surfaces are like the dominant component behind FA electrosynthesis under these conditions. In contrast, we hypothesized that electrochemically generated defects or surface/subsurface oxygen species remaining after the $\mathrm{CuO}_{x}$ layer reduction were primarily responsible for 2-MF generation. We confirmed this by electrochemically roughening the single crystal $\mathrm{Cu}$ surfaces and testing their activity. Indeed, 2-MF production could be recovered on the $\mathrm{Cu}(100)$ and $\mathrm{Cu}(100)$ substrates, through $\mathrm{Cu}(110)$ continued to exhibit selectivity for primarily FA (Fig S5). These results effectively establish a surface structural basis of $\mathrm{Cu}$ for directing selectivity of furfural reduction pathways.

Combining the above results, we proposed a possible mechanism of furfural reduction (Fig S6). At the initial stage of the reaction, the copper oxide surface layer is reduced to metallic copper and protons are reduced to $\mathrm{H}$ atoms $\left(\mathrm{H}_{\mathrm{ads}}\right)$ on the metallic surface. In parallel, furfural adsorbs onto the surface. Subsequently, $\mathrm{H}_{\text {ads }}$ will interact with absorbed furfural molecule and hydrogenate aldehyde group leading to the formation of a $\mathrm{C}-\mathrm{O}$ bond and $\mathrm{O}-\mathrm{H}$ bond. If this intermediate desorbed from the surface of the catalyst, FA will form as the final product. This is the dominant pathway on $\mathrm{Cu}(110)$ However, if the intermediate is retained on the surface and the carbon is further hydrogenated by $\mathrm{H}_{\text {ads }}$, the alcohol $\mathrm{C}-\mathrm{O}$ bond is cleaved and 2-MF is formed. This mechanism insists that the formation of FA and 2-MF share a same intermediate. We can rule out the sequential reduction of FA into 2-MF as significant contributor as no 2-MF products were detected in FA reduction electrolysis.

To conclude, 2-MF and FA were obtained as the principal products of furfural reduction reaction with $\mathrm{R}-\mathrm{Cu}$ electrocatalysts. Operando Raman spectroscopy illustrated that the intermediate formation occurred as the $\mathrm{CuO}_{x}$ layer was reduced away and enabled the proposal of a possible reaction mechanism. Investigation of single crystal $\mathrm{Cu}$ substrates demonstrated that $\mathrm{Cu}(110)$ has the best selectivity for FA production, while the defects likely contribute to 2-MF formation. This work puts forth a structural basis to the relationship between the catalytic activity and active species, 
key for catalyst design across a wide variety of electrosynthetic systems.

\section{Conflicts of interest}

There are no conflicts to declare.

\section{Notes and references}

S. Chu and A. Majumdar, Nature, 2012, 488, 294-303. V. R. Stamenkovic, D. Strmcnik, P. P. Lopes and N. M. Markovic, Nature Mater., 2017, 16, 57-69. Y. Yan, J. L. Hitt, J. A. Turner and T. E. Mallouk, Proc. Natl. Acad. Sci. U.S.A., 2020, 117, 12558. L. Du, Y. Shao, J. Sun, G. Yin, C. Du and Y. Wang, Catal. Sci. Technol., 2018, 8, 3216-3232.

5 J.-P. Lange, E. van der Heide, J. van Buijtenen and R. Price, ChemSusChem, 2012, 5, 150-166. R. Mariscal, P. Maireles-Torres, M. Ojeda, I. Sádaba and M. López Granados, Energy Environ. Sci., 2016, 9, 11441189. A. S. May and E. J. Biddinger, ACS Catal., 2020, 10, 3212 3221.

Y. Kwon, K. J. P. Schouten, J. C. van der Waal, E. de Jong and M. T. M. Koper, ACS Catal., 2016, 6, 6704-6717.

X. H. Chadderdon, D. J. Chadderdon, J. E. Matthiesen, Y. Qiu, J. M. Carraher, J.-P. Tessonnier and W. Li, J. Am. Chem. Soc., 2017, 139, 14120-14128.

P. Nilges and U. Schröder, Energy Environ. Sci., 2013, 6, 2925-2931.

Y. Cao and T. Noël, Org. Process Res. Dev., 2019, 23, 403408.

S. Jung and E. J. Biddinger, ACS Sustainable Chem. Eng., 2016, 4, 6500-6508.

W. C. Albert and A. Lowy, Trans. Electrochem. Soc., 1939, 75, 367.

S. Jung, A. N. Karaiskakis and E. J. Biddinger, Catal. Today, 2019, 323, 26-34.

S. Jung and E. J. Biddinger, Energy Tech., 2018, 6, 13701379.

I. V. Chernyshova, P. Somasundaran and S. Ponnurangam, Proc. Natl. Acad. Sci. U.S.A., 2018, 115, E9261.

N. Heidary, K. H. Ly and N. Kornienko, Nano Lett., 2019, 19, 4817-4826.

N. Heidary and N. Kornienko, Chem. Commun., 2020, 56, 8726-8734.

L. Strandman-Long and J. Murto, Spectrochim. Acta, Part A, 1981, 37, 643-653.

T.-j. Jia, P.-w. Li, Z.-g. Shang, L. Zhang, T.-c. He and Y.-j. Mo, J. Mol. Struct., 2008, 873, 1-4.

T. Kim, R. S. Assary, L. A. Curtiss, C. L. Marshall and P. C. Stair, J. Raman Spectrosc., 2011, 42, 2069-2076.

M. He, C. Li, H. Zhang, X. Chang, J. G. Chen, W. A. Goddard, M.-j. Cheng, B. Xu and Q. Lu, Nature Commun., 2020, 11, 3844.

Y. Deng, A. D. Handoko, Y. Du, S. Xi and B. S. Yeo, ACS
E. Bennett, T. Wilson, P. J. Murphy, K. Refson, A. C. Hannon, S. Imberti, S. K. Callear, G. A. Chass and S. F. Parker, Inorg. Chem., 2015, 54, 2213-2220.

J. F. Li, Y. F. Huang, Y. Ding, Z. L. Yang, S. B. Li, X. S. Zhou, F. R. Fan, W. Zhang, Z. Y. Zhou, D. Y. Wu, B. Ren, Z. L. Wang and Z. Q. Tian, Nature, 2010, 464, 392-395.

K. O. Bugaev, A. A. Zelenina and V. A. Volodin, Int. J. Raman. Spec., 2012, 2012, 281851. Catal., 2016, 6, 2473-2481. 
Supplementary information for: Probing electrosynthetic reactions with furfural on copper surfaces

Junnan $\mathrm{Li}^{\mathrm{a}}$ and Nikolay Kornienko ${ }^{\mathrm{a} *}$

${ }^{a}$ Department of Chemistry, Université de Montréal, 1375 Ave. Thérèse-Lavoie-Roux, Montréal, $Q C H 2 V O B 3$

*email: Nikolay.kornienko@umontreal.ca 


\section{Materials and methods:}

$\mathrm{Cu}$ synthesis:

Rough $\mathrm{Cu}$ foil was obtained by an electrochemical roughening method. Commercial $\mathrm{Cu}$ foil was cut to a suitable size as the precursor, and polished with $\mathrm{Al}$ powder. Then the $\mathrm{Cu}$ foil was washed by DI water and ultrasonic to remove the impurities on the surface. After this procedure, the $\mathrm{Cu}$ foil was used as working electrode in a three-electrode system $(\mathrm{Ag} / \mathrm{AgCl}$ as reference, carbon rod as counter), with $\mathrm{CO}_{2}$-saturated $\mathrm{KHCO}_{3}$ as electrolyte, 6 cyclic voltammetry cycles were conducted in the range of 0 to $-1.6 \mathrm{~V}$ (vs. $\mathrm{Ag} / \mathrm{AgCl}$ ), with a scan rate at $50 \mathrm{mV} / \mathrm{s}$. Subsequently, chronoamperometry was carried out at $+0.9 \mathrm{~V}$ for $1 \mathrm{~min}$ to oxidize the $\mathrm{Cu}$ foil, followed by the reduction process at $-0.3 \mathrm{~V}$ for 10 mins. The illustration of the roughening scheme is shown as Figure 2.

Physical characterization:

X-ray diffraction (XRD) patterns were measured on a Bruker D8 Advance diffractometer with a $\mathrm{Cu} \mathrm{K} \alpha$ radiation source $(\lambda=1.5418 \AA$ ). High-resolution x-ray photoelectron spectroscopy (XPS) measurements were conducted on a Vacuum Generator Escalab 220i XL X-ray photoelectron spectrometer, calibrated by using carbon (C1s $284.6 \mathrm{eV})$. Transmission electron microscopic (TEM) images were performed on JEOL JEM-2100F FEG-TEM, operated at $200 \mathrm{kV}$. The sample was scratched from rough $\mathrm{Cu}$ foil on to carbon film.

Electrochemistry and product quantification:

Cyclic voltammetry (CV) and other electrochemical techniques were performed using a Bio-Logic SP-150 Potentiostat (BioLogic Science Instruments, France). A three-electrode system has been employed by applying the above rough $\mathrm{Cu}$ foil as the working electrode, $\mathrm{Ag} / \mathrm{AgCl}$ as the reference electrode and a $\mathrm{Pt}$ wire as the counter electrode. $\mathrm{K}_{2} \mathrm{SO}_{4}$ solution $\left(1 \mathrm{M}\right.$, with added $\mathrm{H}_{2} \mathrm{SO}_{4}$ to adjust to $\mathrm{pH} 3$ ) was used as the electrolyte in the measurements. The CVs were measured in the range of $0 \sim-0.526 \mathrm{~V}$ (vs. RHE) at a sweep rate of $20 \mathrm{mV} \mathrm{s}^{-1}$. Potentiostatic electrolysis was conducted in a two-compartment custom built glass $\mathrm{H}$-cell reactor.

The anode and cathode chambers were separated by a glass frit. Before each electrolysis experiment, $20 \mathrm{ml}$ electrolyte was added into the reactor and purged with $\mathrm{N}_{2}$ for 15 mins to remove dissolved gases. The reactor was sealed and the electrolyte was stirred at $500 \mathrm{rpm}$ during the reaction. All reactions were carried out at room temperature.

In order to analyze the products of the reaction, gas chromatography (GC, SRI 8610C, Mandel) and NMR (Bruker AVANCE II 400 se) were performed to reveal the content and composition of the gas and liquid products respectively. After $3 \mathrm{hs}$ electrolysis, $10 \mathrm{~mL}$ gas was extracted from the reactor by syringe and injected into GC to test the content of hydrogen. $400 \mu \mathrm{L}$ liquid product was mixed with $100 \mu \mathrm{L} \mathrm{D} \mathrm{D}_{2} \mathrm{O}$ to test the NMR and investigate the content of furfural alcohol (FA) and 2-methylfuran (MF). The faradaic efficiency (FE) was calculated by using the following formula: 
$\varepsilon_{\mathrm{FE}}=\frac{\alpha n F}{Q}$

where $\alpha$ is electron transfer numbers (for the formation of $\mathrm{H}_{2}$ and FA is 2 , MF is 4 ), $\mathrm{n}$ is the moles of the products, $\mathrm{F}$ is faraday constant $\left(96485 \mathrm{C} \mathrm{mol}^{-1}\right), \mathrm{Q}$ is the charge passed in total during the reaction.

\section{Raman spectroscopy:}

A three-electrode electrochemical cell was used for in-situ Raman experiment. Titanium foil was used as the counter electrode, $\mathrm{Ag} / \mathrm{AgCl}$ was used as reference, and rough $\mathrm{Cu}$ foil as working electrode in a custom-built Teflon spectroelectrochemical cell. The scheme was shown in the main text Figure 1. The electrolyte is $1 \mathrm{M} \mathrm{K}_{2} \mathrm{SO}_{4}$ (with $\mathrm{H}_{2} \mathrm{SO}_{4}, \mathrm{pH} 3$ ), which is also bubbled with $\mathrm{N}_{2}$ for 15 mins to remove the dissolved gas. Raman spectroscopy were recorded on a Renishaw InVia Raman Microscope and excited with $633 \mathrm{~nm}$ excitation laser. 


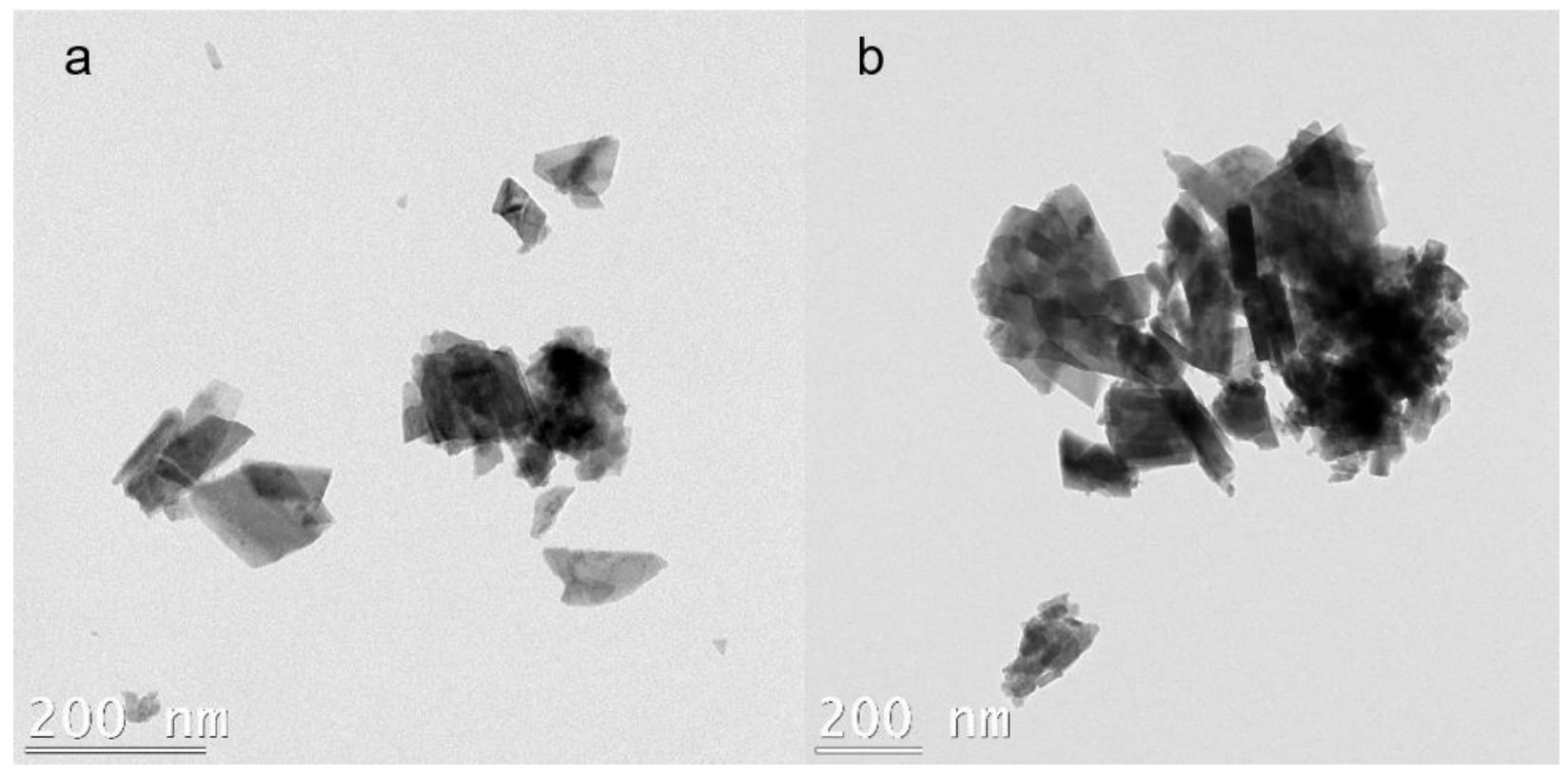

Figure S1. TEM images of rough $\mathrm{Cu}$ foil. 

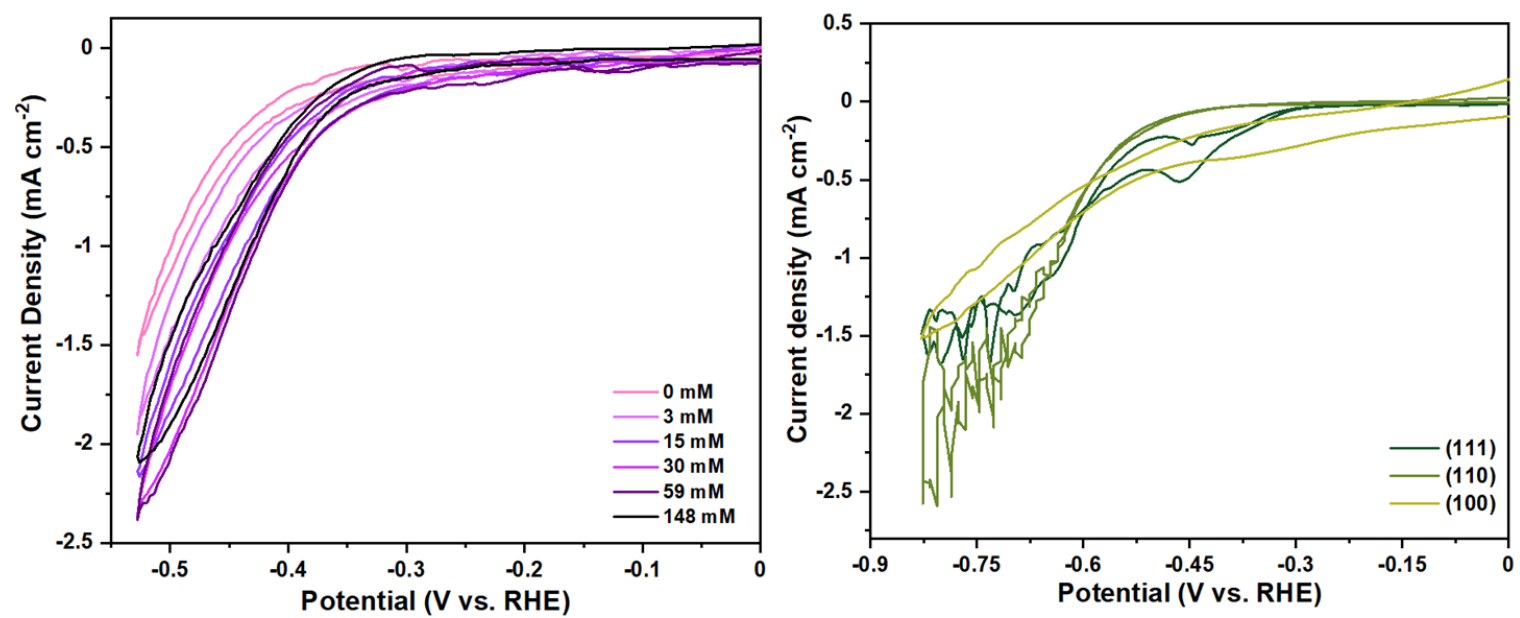

Figure $\mathrm{S} 2$. CV curves of (a) rough $\mathrm{Cu}$ foil with different amount of furfural; (b) single crystal $\mathrm{Cu}$ foil with $59 \mathrm{mM}$ furfural. 

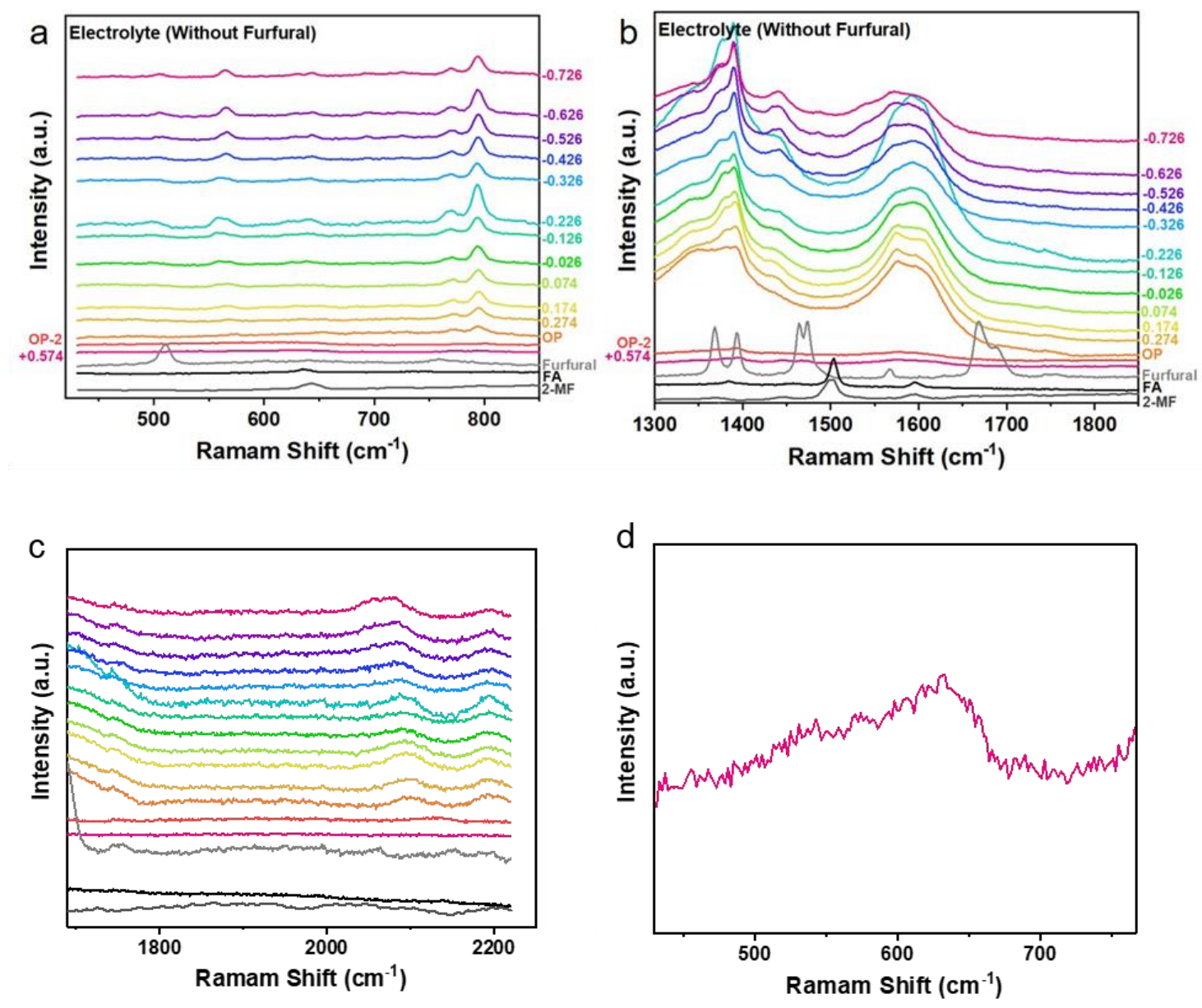

Figure S3. Operando SER spectra on $\mathrm{R}-\mathrm{Cu}$ surface without adding furfural in the (a) low frequency (b) medium frequency and (c) high frequency regions. A zoomed in spectra of the $\mathrm{R}-\mathrm{Cu}$ at open circuit potentials is also illustrated to clearly show the spectrum corresponding to the $\mathrm{CuO}_{\mathrm{x}}$ surface. 

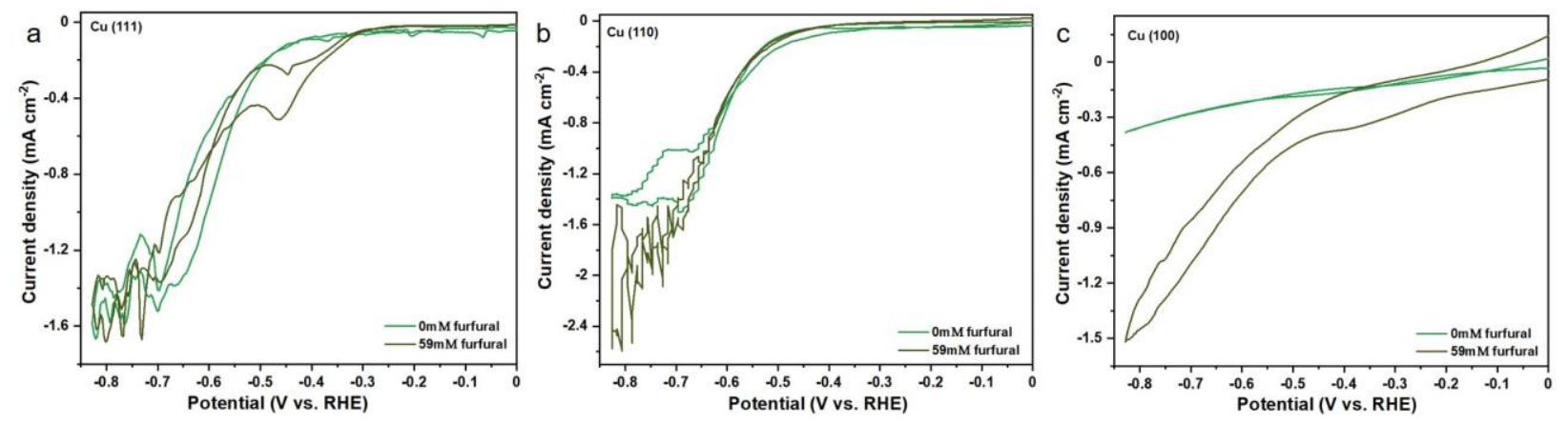

Figure S4. CV curves of single crystal $\mathrm{Cu}$ (a) $\mathrm{Cu}$ (111); (b) $\mathrm{Cu}$ (110); (c) $\mathrm{Cu}(100)$ with (dark green) and without furfural (light green). 

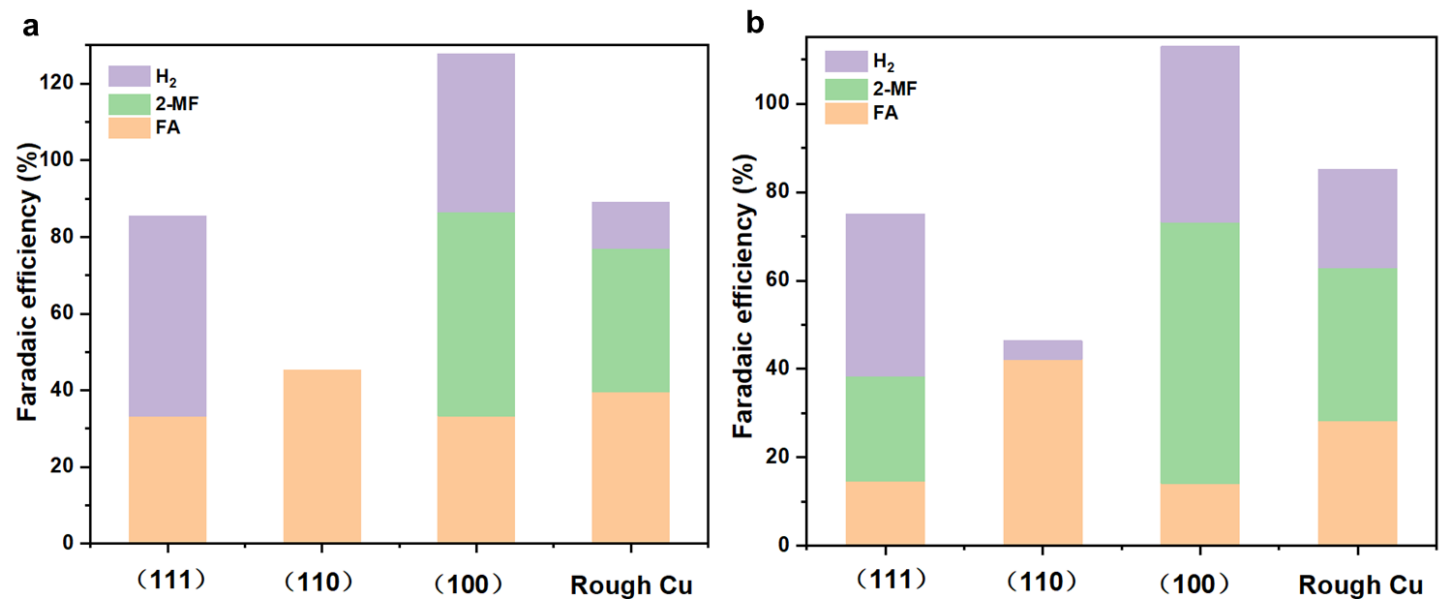

Figure S5. Faradaic efficiency of roughen single crystal $\mathrm{Cu}$ under with $59 \mathrm{mM}$ furfural at different applied potential (a) $-0.526 \mathrm{~V}$; (b) $-0.726 \mathrm{~V}$ vs. RHE. 


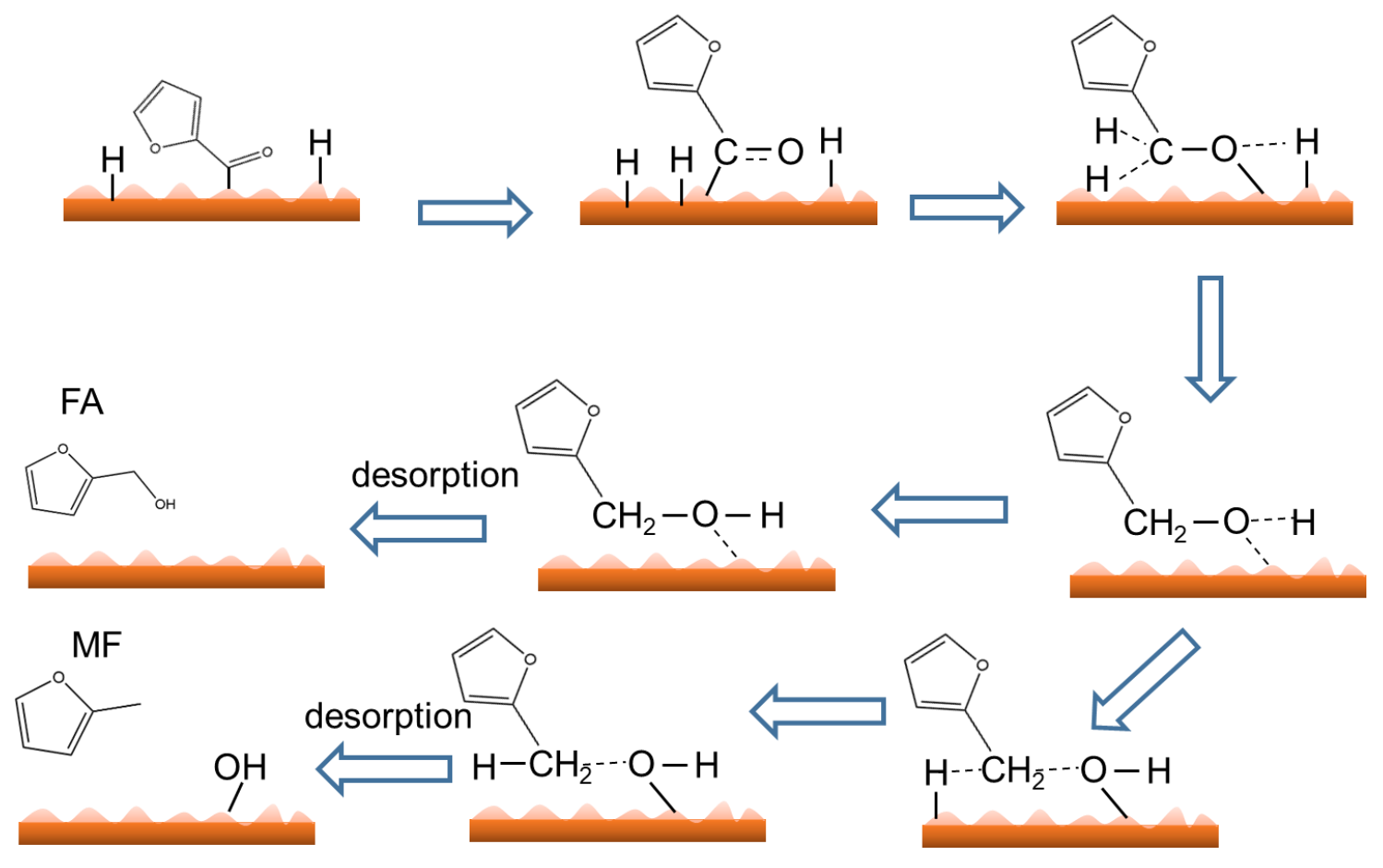

Figure S6. Proposed mechanism of furfural reduction reaction on R-cu. 